\title{
Medullary carcinoma of the colon: a distinct morphology reveals a distinctive immunoregulatory microenvironment
}

\author{
Kenneth Friedman ${ }^{1}$, Alexander S Brodsky ${ }^{1}$, Shaolei Lu ${ }^{1}$, Stephanie Wood ${ }^{1}$, Anthony J Gill ${ }^{2}$, \\ Kara Lombardo ${ }^{1}$, Dongfang Yang $^{1}$ and Murray B Resnick ${ }^{1}$ \\ ${ }^{1}$ Department of Pathology and Laboratory Medicine, Rhode Island Hospital and Alpert Medical School of \\ Brown University, Providence, RI, USA and ${ }^{2}$ Department of Anatomical Pathology, Royal North Shore \\ Hospital, Sydney, NSW, Australia
}

\begin{abstract}
Medullary carcinoma of the colon is a unique histologic subtype of microsatellite unstable colorectal carcinoma but little is known regarding its tumor-immunoregulatory microenvironment. The aims of this study were to characterize the immune environment of medullary carcinoma and compare it with other microsatellite unstable and microsatellite stable colorectal carcinomas. An initial gene expression microarray analysis of six cases of medullary carcinoma was used to detect potentially differentially expressed genes. We extended this analysis utilizing genomic data from the Cancer Genome Atlas to compare eight cases of medullary carcinoma with other microsatellite unstable and stable carcinomas. Finally, we evaluated expression of key immune pathway proteins and lymphocyte subsets via immunohistochemistry of a large group of medullary carcinomas $(n=105)$ and compared these findings with three other groups: poorly differentiated, microsatellite unstable well-differentiated and microsatellite stable well-differentiated carcinomas. Microarray and the Cancer Genome Atlas data analysis identified significant upregulation of several immunoregulatory genes induced by IFN $\gamma$ including IDO-1, WARS (tRNA(trp)), GBP1, GBP4, GBP5, PDCD1 (PD-1), and CD274 (PD-L1) in medullary carcinoma compared with other microsatellite unstable and microsatellite stable tumors. By immunohistochemistry, IDO-1 was expressed in $64 \%$ of medullary carcinomas compared with $19 \%(9 / 47)$ of poorly differentiated carcinomas, $14 \%(3 / 22)$ of microsatellite unstable, and $7 \%(2 / 30)$ of the microsatellite stable well-differentiated carcinomas $(P<0.0001)$. tRNA(trp) was overexpressed in $81 \%(84 / 104)$ of medullary carcinomas, $19 \%(9 / 47)$ of poorly differentiated, $32 \%$ (7/22) of microsatellite unstable, and $3 \%(1 / 30)$ of microsatellite stable well-differentiated carcinomas $(P<0.0001)$. Medullary carcinoma had higher mean CD8+ and PD-L1+ tumor-infiltrating lymphocytes compared with all other groups $(P<0.0001)$. This study demonstrates overexpression of several immunoregulatory genes in microsatellite unstable colorectal carcinomas and that expression of these genes and proteins is more prevalent in the medullary carcinoma subtype, which may be of use both diagnostically and therapeutically. Modern Pathology (2016) 29, 528-541; doi:10.1038/modpathol.2016.54; published online 11 March 2016
\end{abstract}

The tumor immune microenvironment is increasingly emerging as an important factor in understanding the behavior and predicting the clinical outcome of a variety of tumors. Tumors with vigorous immune responses often contain higher amounts of tumor-infiltrating lymphocytes as a distinguishing feature. ${ }^{1}$ Microsatellite unstable

Correspondence: Dr MB Resnick, MD, PhD, Department of Pathology and Laboratory Medicine, Rhode Island Hospital and Alpert Medical School of Brown University, 593 Eddy Street, Providence, RI 02903, USA.

E-mail: mresnick@lifespan.org

Received 12 January 2016; revised 9 February 2016; accepted 9 February 2016; published online 11 March 2016 colorectal carcinomas characteristically contain higher numbers of tumor-infiltrating lymphocytes, ${ }^{2}$ presumably in response to a milieu of neopeptides generated by frameshift mutations caused by defective mismatch-repair proteins. ${ }^{3}$ As a group, microsatellite unstable colorectal carcinomas have a more indolent clinical course with a more favorable prognosis over microsatellite stable colorectal carcinomas. ${ }^{4,5}$ This holds true even for medullary carcinoma of the colon, a unique subtype of microsatellite unstable CRC, where the histomorphology of an 'undifferentiated' or 'poorly differentiated' pattern would seem to suggest otherwise. Yet investigators have consistently demonstrated improved prognosis of medullary carcinomas over other colorectal carcinomas, ${ }^{6-9}$ with 
lower rates of locoregional nodal involvement and distant metastasis. ${ }^{8,9}$

Active immune recognition in these tumors is postulated to be at least partly responsible for the more favorable associated clinical outcomes. Tumor cells expressing antigen become targets for a T-cellmediated adaptive immune response, characterized by a shift toward a T-helper type 1 phenotype and production of interferon-gamma (IFN $\gamma)^{1,10,11}$ This environment promotes CD8+ cytotoxic T-cell proliferation, which has been consistently observed in microsatellite unstable colorectal carcinomas compared with microsatellite stable tumors. In addition CD3+ lymphocytes, CD45RO effector $\mathrm{T}$ cells, and CD4+ $\mathrm{T}$ lymphocytes have all been observed at higher amounts in the tumor, tumor front, and stroma in microsatellite unstable vs microsatellite stable colorectal carcinomas. ${ }^{11,12}$

In light of these robust immune antitumor responses, most cancers progress and evade immune system-mediated destruction owing to the presence of multiple regulatory checkpoints that tip the balance toward immune inhibition. One such pathway involves programmed cell death receptor 1 (PD-1) and its ligand (PD-L1). PD-1 is expressed on activated tumor-infiltrating $\mathrm{T}$ cells from many tumor types and when engaged with PD-L1 induces downregulation of TIL proliferation ${ }^{13}$ and cytokine production with induction of immunologic tolerance. ${ }^{14}$ PD-L1 is constitutively expressed by T and B cells but is overexpressed by many tumors ${ }^{15}$ and can shut down specific immune responses, including suppression of cytolytic activity of CD8+ T cells. ${ }^{16}$

These immune checkpoint-related proteins such as PD-1 and PD-L1 have recently been found to be overexpressed in the tumor microenvironment of microsatellite unstable colorectal carcinomas collectively. ${ }^{12,17}$ However, data regarding differences in the tumor immune microenvironment among varying histologic subtypes of microsatellite unstable colorectal carcinomas is limited. Given that medullary carcinoma represents a distinct histologic subtype with a paradoxically favorable clinical outcome, we decided to take a more comprehensive look at the microenvironment of medullary carcinoma and compare it with that seen in poorly differentiated, and both microsatellite unstable well-differentiated and microsatellite stable well-differentiated colorectal carcinomas. Using a combination of gene expression analysis, immunohistochemistry and comparison with genomic data available from the Cancer Genome Atlas we found significant differences in lymphocyte subsets and checkpoint regulators between medullary carcinoma and other microsatellite unstable and microsatellite stable tumors. These data are clinically relevant given that clinical trials involving checkpoint blockade agents are being investigated for patients with microsatellite unstable tumors. ${ }^{18}$

\section{Materials and methods}

\section{Patients and Samples}

The study was approved by the Institutional Review Board at the Rhode Island Hospital. Cases were selected by reviewing written pathology reports of all colon cancer patients diagnosed between the years 1995 and 2015 at the Rhode Island and Miriam Hospitals searching for keywords 'high grade', 'poorly differentiated', and 'medullary.' A total of 21 medullary carcinomas and 47 poorly differentiated adenocarcinomas were identified. In addition, a separate keyword search for microsatellite instable tumors was conducted and 22 well-differentiated microsatellite unstable tumors were collected based on absent mismatch-repair proteins by immunohistochemistry. An additional 30-stage-matched well-differentiated microsatellite stable tumors were chosen for comparison.

An additional 84 cases of medullary carcinoma were collected in collaboration with Royal North Shore Hospital, St Leonards Australia. The computerized colorectal specimen database in the Department of Anatomical Pathology was searched for cases of CRC diagnosed from June 1998 to April 2014 using the keywords 'medullary' and 'colon.' Cases prospectively diagnosed as medullary carcinoma from pathology reports underwent review by a gastrointestinal pathologist (AJG) for confirmation of the diagnosis. In addition, a previously constructed tissue microarray of colorectal carcinoma was inspected to identify further cases of medullary carcinoma and if a case with potential medullary morphology was detected, whole H\&E sections of the case were reviewed by the gastrointestinal pathologist (AJG) for confirmation.

Medullary carcinoma for both cohorts was defined by applying strict morphologic criteria and demonstration of mismatch-repair protein deficiency by immunohistochemistry. At least $90 \%$ of the tumor had to contain a solid and syncytial growth pattern (sheets, nests, or trabeculae) consisting of mediumsized cells with vesicular nuclei and prominent nucleoli with a pushing or expansile pattern of growth. ${ }^{19}$ Poorly differentiated (high grade) carcinomas were defined as having $0-49 \%$ gland formation and well-differentiated carcinomas (low grade) were defined as having $50-100 \%$ gland formation according to the WHO. ${ }^{20}$

\section{Tissue Microarray Construction}

Areas of pure invasive carcinoma from each tumor subset were first identified on hematoxylin and eosin-stained slides from each case. The corresponding areas were marked on the paraffin block. The blocks were cored at a diameter of $1 \mathrm{~mm}$ and transferred to a masterblock using the Beecher Tissue Microarrayer (Beecher Instruments, Silver Spring, MD, USA). Two to five cores of tumor and 
Table 1 Summary of antibodies and methods used for immunohistochemistry

\begin{tabular}{|c|c|c|c|c|c|}
\hline Antibody & Source & Host & Antigen retrieval & Dilution & Detection method \\
\hline IDO-1 & $\begin{array}{l}\text { Millipore, Billerica, } \\
\text { MA, USA }\end{array}$ & $\begin{array}{l}\text { Mouse Monoclonal } \\
\text { Clone } 10.1\end{array}$ & $\begin{array}{l}\text { EDTA pH } 9 \text { Microwave } \\
120^{\circ} \mathrm{C}, 10 \mathrm{~min}\end{array}$ & $1: 25$ & Dako Envision+Kit \\
\hline WARS & $\begin{array}{l}\text { Abcam, Cambridge, } \\
\text { MA, USA }\end{array}$ & $\begin{array}{l}\text { Rabbit Monoclonal, } \\
\text { Clone EPR3423 }\end{array}$ & $\begin{array}{l}\text { EDTA pH } 9 \text { Microwave } \\
120^{\circ} \mathrm{C}, 10 \mathrm{~min}\end{array}$ & $1: 4000$ & Dako Envision+Kit \\
\hline CD3 & $\begin{array}{l}\text { Dako, Carpenteria, CA, } \\
\text { USA }\end{array}$ & Rabbit Polyclonal & $\begin{array}{l}\text { EDTA pH } 9 \text { Dako } \\
\text { PTLink } 97^{\circ} \mathrm{C}, 20 \mathrm{~min}\end{array}$ & RTU & $\begin{array}{l}\text { Dako Envision FLEX } \\
\text { Autostainer }\end{array}$ \\
\hline GBP5 & $\begin{array}{l}\text { Proteintech, Chicago, } \\
\text { IL, USA }\end{array}$ & Rabbit Polyclonal & $\begin{array}{l}\text { EDTA pH } 9100^{\circ} \mathrm{C} \text {, } \\
40 \mathrm{~min}\end{array}$ & 1:1000 & $\begin{array}{l}\text { Ventana Discovery } \\
\text { DabMap Kit }\end{array}$ \\
\hline PD-1 & $\begin{array}{l}\text { Abcam, Cambridge, } \\
\text { MA, USA }\end{array}$ & $\begin{array}{l}\text { Mouse Monoclonal, } \\
\text { Clone NAT105 }\end{array}$ & $\begin{array}{l}\text { EDTA pH } 9100{ }^{\circ} \mathrm{C}, \\
40 \text { min }\end{array}$ & $1: 100$ & $\begin{array}{l}\text { Ventana Discovery } \\
\text { DabMap Kit }\end{array}$ \\
\hline PDL1 & $\begin{array}{l}\text { Abcam, Cambridge, } \\
\text { MA, USA }\end{array}$ & $\begin{array}{l}\text { Rabbit Monoclonal, } \\
\text { Clone EPR1161 }\end{array}$ & $\begin{array}{l}\text { EDTA pH } 9100^{\circ} \mathrm{C} \text {, } \\
40 \text { min }\end{array}$ & 1:1500 & $\begin{array}{l}\text { Ventana Discovery } \\
\text { DabMap Kit }\end{array}$ \\
\hline FOXP3 & $\begin{array}{l}\text { Abcam, Cambridge, } \\
\text { MA, USA }\end{array}$ & $\begin{array}{l}\text { Mouse Monoclonal, } \\
\text { Clone 236A/E7 }\end{array}$ & $\begin{array}{l}\text { EDTA pH } 9100^{\circ} \mathrm{C} \text {, } \\
40 \text { min }\end{array}$ & $1: 100$ & $\begin{array}{l}\text { Ventana Discovery } \\
\text { DabMap Kit }\end{array}$ \\
\hline CD8 & $\begin{array}{l}\text { Vector Laboratories, } \\
\text { Burlingame, CA, USA }\end{array}$ & $\begin{array}{l}\text { Mouse Monoclonal, } \\
\text { Clone 4B11 }\end{array}$ & $\begin{array}{l}\text { EDTA pH9 } 100{ }^{\circ} \mathrm{C} \text {, } \\
40 \text { min }\end{array}$ & $1: 200$ & $\begin{array}{l}\text { Ventana Discovery } \\
\text { DabMap Kit }\end{array}$ \\
\hline
\end{tabular}

one core of histologically normal adjacent colonic mucosa were arrayed for every case.

\section{Immunohistochemistry}

Table 1 contains a summary of the immunohistochemical stains used. In brief, stains for each antigen were performed on $5 \mu \mathrm{m}$ paraffin sections of each tissue microarray masterblock. The panel included antibodies against IDO-1 (mouse monoclonal, clone 10.1, 1:25, Millipore, Billerica, MA, USA), tryptophanyl-tRNA-synthetase (tRNA(trp), WARS) (rabbit monoclonal, clone EPR3423, 1:4000, Abcam, Cambridge, MA, USA), GBP5 (rabbit polyclonal, 1:1000, Proteintech, Chicago, IL, USA), CD3 (rabbit polyclonal, RTU, DAKO, Carpinteria, CA, USA), CD8 (mouse monoclonal, clone 4B11, 1:200, Vector Laboratories, Burlingame, CA, USA), Foxp3 (mouse monoclonal, clone 236A/E7, 1:100, Abcam), PD-1 (mouse monoclonal, clone NAT105, 1:100, Abcam), and PD-L1 (rabbit monoclonal, clone EPR1161, 1:1500, Abcam). The stains were either run on the Ventana Discovery Autostainer using the DabMap Detection Kit, the Ventana Benchmark Ultra Autostainer using the ultraView Detection Kit (Ventana Medical Systems, Tucson, AZ, USA), or the Dako autostainer using the Envision Plus kit (Dako, Carpinteria, CA, USA). Slides were counterstained with hematoxylin, dehydrated, and coverslipped. Positive controls included normal lymph node (IDO-1, GBP5), normal tonsil (PD-L1, PD-1, Foxp3), and breast carcinoma (tRNA(trp) or WARS).

\section{Immunohistochemical Assessment and Scoring}

Immunohistochemical stains for IDO-1, tRNA(trp), and guanylate-binding proteins (GBP5) were evaluated in epithelium and surrounding stroma. PD-L1 was evaluated within the epithelium and within intratumoral-infiltrating lymphocytes. PD-1 was evaluated only in lymphocytes. Epithelial staining was considered negative if there was absent or barely perceptible staining at $10 \times$, moderate if easily identifiable at $10 \times$ and intense if easily identifiable at $2 \times$. Only cases with moderate-to-intense staining intensity were considered positive. The extent of staining was scored as $0-3 \quad(0=0 \% ; 1=<25 \%$; $2=25-50 \% ; 3=>50 \%)$ for epithelium and $0-2$ $(0=0 \%, 1=0-50 \%, 2=>50 \%)$ for stroma based on percentage of positive cells. These cutoffs were determined and scored by a single observer (MR) to minimize interobserver variability. Intraepithelial and stromal lymphocytes positive for PD-L1, Foxp3, PD-1, and CD8 were manually counted and the counts per core were averaged for each tumor.

\section{Laser Capture Microdissection and RNA Extraction}

Six cases of medullary carcinoma with paired adjacent normal colonic mucosa were used for gene expression analysis. Tissue sections of $10 \mu \mathrm{m}$ were cut and mounted onto plain glass slides for manual microdissection or PEN membrane slides (Life Technologies, Carlsbad, CA, USA) for UV laser capture microdissection. The sections were de-paraffinized, stained, dehydrated through graded alcohols using the Paradise formalin-fixed paraffinembedded reagent System (Life Technologies) and subjected to manual microdissection or UV laser capture microdissection within $2 \mathrm{~h}$ of deparaffinization. Care was taken to capture areas with similar proportions of cancer cells. Laser-captured cells were collected on LCM Macro CapSure caps (Life Technologies) using the Arcturus XT LCM instrument (Life Technologies). Total RNA (containing both mRNA and microRNA) was extracted using the RecoverAll Total Nucleic Acid Extraction Kit for formalin-fixed paraffin-embedded tissues, with DNAse incubation (Life Technologies). 
Table 2 Clinicopathologic characteristics of 105 cases of medullary carcinoma, 47 cases of poorly differentiated, 22 cases of microsatellite unstable well-differentiated and 30 cases of microsatellite stable well-differentiated carcinomas

\begin{tabular}{|c|c|c|c|c|c|}
\hline $\begin{array}{l}\text { Clinicopathologic } \\
\text { features }\end{array}$ & $\begin{array}{l}\text { Medullary } \\
(\mathrm{n}=105)\end{array}$ & $\begin{array}{l}\text { Poorly differentiated } \\
\qquad(\mathrm{n}=47)\end{array}$ & $\begin{array}{l}\text { Microsatellite unstable well } \\
\text { differentiated }(\mathrm{n}=22)\end{array}$ & $\begin{array}{l}\text { Microsatellite stable well } \\
\text { differentiated }(\mathrm{n}=30)\end{array}$ & P-value \\
\hline \multicolumn{6}{|l|}{ Age at surgery } \\
\hline Mean & 78.9 & 71.7 & 73.6 & 67.5 & \multirow[t]{2}{*}{$7.11 \times 10^{-6}$} \\
\hline Range & $50-97$ & $27-95$ & $40-95$ & $39-86$ & \\
\hline \multicolumn{6}{|l|}{ Sex } \\
\hline Male & $19(18 \%)$ & $19(40 \%)$ & $11(50 \%)$ & $15(50 \%)$ & \multirow{2}{*}{0.0003} \\
\hline Female & $86(82 \%)$ & $28(60 \%)$ & $11(50 \%)$ & $15(50 \%)$ & \\
\hline \multicolumn{6}{|l|}{ Location } \\
\hline Right & $91(87.5 \%)$ & $38(80.9 \%)$ & $19(86.4 \%)$ & $16(53.3 \%)$ & \multirow[t]{2}{*}{$4 \times 10^{-8}$} \\
\hline Left & $13(12.5 \%)$ & $9(19.1 \%)$ & $3(13.6 \%)$ & $14(46.6 \%)$ & \\
\hline \multicolumn{6}{|l|}{ Final stage } \\
\hline I & $9(8.7 \%)$ & $2(4.3 \%)$ & $7(31.8 \%)$ & $4(13.3 \%)$ & \multirow[t]{4}{*}{0.0013} \\
\hline II & $51(49.5 \%)$ & $14(29.8 \%)$ & $10(45.5 \%)$ & $14(46.7 \%)$ & \\
\hline III & $41(39.8 \%)$ & $25(53.2 \%)$ & $5(22.7 \%)$ & $10(33.3 \%)$ & \\
\hline IV & $2(1.9 \%)$ & $6(12.8 \%)$ & 0 & $2(6.7 \%)$ & \\
\hline Tumor size (cm) & 6.38 & 6.25 & 5.35 & 4.87 & 0.0247 \\
\hline
\end{tabular}

\section{RNA Expression Analysis}

RNA was prepared following the manufacturer's instructions. In brief, RNA was isolated and purified using the RNeasy formalin-fixed paraffin-embedded kit (Qiagen, Valencia, CA, USA). In total, $100 \mathrm{ng}$ of total RNA was amplified using Affymetrix Sensation Plus formalin-fixed paraffin-embedded amplification kit following the manufacturer's instructions and labeled cDNA was hybridized to Affymetrix (Santa Clara, CA, USA) HTA 2.0 microarrays and visualized at the Brown University Genomics Core Facility following the manufacturer's instructions. Signals were estimated using RMA. ${ }^{21} P$-values were calculated using a pairwise one-way variance analysis (ANOVA) between each normal and tumor pair and $q$-values calculated in R using the $q$-value package. ${ }^{22}$ Functional analyses were performed using Gene Ontology annotations ${ }^{23}$ and Gene Set Enrichment Analysis (GSEA). ${ }^{24}$ Data are available in GEO, GSE76855.

\section{The Cancer Genome Atlas Analysis}

Cases of medullary carcinoma were screened using $\mathrm{cBioPortal}^{25}$ for microsatellite unstable status and only cases with tissue images available that met histologic criteria for medullary carcinoma as above were chosen for analysis. Clinical data were downloaded from the Cancer Genome Atlas data portal (https://tcga.data.nci.gov/tcga/dataAccessMatrix.

$\mathrm{htm}$, download in September 2015). Molecular subtypes (microsatellite unstable-high, microsatellite unstable-low, and microsatellite stable) were acquired in the Cancer Genome Atlas clinical data. Normalized RNA-seq data for colorectal tumors were downloaded from Firebrowse in September 2015. ${ }^{26}$ The GAII and HiSeq data sets were kept separate.
Fold change, $t$-tests, and multiple hypothesis tests were calculated in $\mathrm{R}$ version3.1.1. Because it is not clear how GSEA accounts for normalization of RNA-seq data, fold changes were calculated for the indicated comparisons and a pre-rank file was generated for analysis as recommended by the GSEA tutorials. Batch effects were considered and found not to be significant in these data as determined by the Cancer Genome Atlas batch effects tool (The Cancer Genome Atlas Batch Effects 2015. Available from: http://bioinformatics.mdanderson.org/tcgambatch/).

\section{Statistical Analysis}

The $\chi^{2}$-analysis was used to assess the immunohistochemical staining scores. ANOVA and $t$-test were used for comparing lymphocyte counts among tumor types and between other characteristics. Pearson's correlation coefficient analysis was used to determine the association among lymphocyte counts. All tests were two-sided with 0.05 as the threshold $P$-value to be considered statistically significant. All analyses were performed using the SAS software, JMP Pro version 11.1 (SAS, Cary, NC, USA).

\section{Results}

\section{Clinicopathologic Features}

The clinicopathologic features are summarized in Table 2. Location and final stage were unavailable for one and two patients with medullary carcinoma, respectively. The mean ages at the time of surgery were 78.9 for medullary carcinoma, 71.7 for poorly differentiated, 73.6 for microsatellite unstable well-differentiated, and 67.5 for microsatellite stable well-differentiated $\left(P=7.11 \times 10^{-6}\right)$. Most medullary 
Table 3 Gene expression microarray data showing differentially expressed genes related to IFN $\gamma$ signaling in six cases of medullary carcinoma compared with adjacent normal mucosa

\begin{tabular}{lccc}
\hline Gene symbol & Fold change tumor vs normal & P-value & q-value \\
\hline IDO-1 & 4.29 & 0.01 & 0.04 \\
WARS & 30.1 & 0.002 & 0.03 \\
GBP1 & 23.39 & 0.003 & 0.03 \\
GBP4 & 13.31 & 0.008 & 0.04 \\
GBP5 & 10.35 & 0.004 & 0.04 \\
IFNG & 1.38 & 0.04 & 0.09 \\
CD274 (PD-L1) & 1.4 & 0.08 & 0.1 \\
PDCD1 (PD-1) & -1.02 & 0.89 & 0.5 \\
\hline
\end{tabular}

carcinoma patients (82\%) were female, whereas $60 \%$ of poorly differentiated, $50 \%$ of microsatellite unstable well-differentiated and $50 \%$ of microsatellite stable well-differentiated patients were female $(P=0.0003)$. Medullary carcinoma occurred more frequently in the right colon $(87.5 \%)$ as did poorly differentiated $(80.9 \%)$, microsatellite unstable well-differentiated $(86.4 \%)$, and microsatellite stable well-differentiated (53.3\%), $\left(P=4 \times 10^{-8}\right)$. Most medullary carcinomas presented at a lower stage comparable to microsatellite unstable well-differentiated and microsatellite stable well-differentiated with most poorly differentiated colorectal carcinomas presenting at higher stage $(P=0.0013)$. Medullary carcinomas and poorly differentiated colorectal carcinomas tended to be larger at presentation than well-differentiated colorectal carcinomas $(P=0.0247)$.

\section{Gene Expression Results}

Of the 32670 genes represented on the microarrays, 7429 were differentially expressed $(P<0.05)$ between medullary carcinoma and adjacent histologically normal colonic mucosa in all six cases. GSEA revealed many biological pathways related to the adaptive inflammatory response, one of the major pathways being that mediated by IFN $\gamma$ (Table 3). Several differentially expressed genes induced by IFN $\gamma$ including IDO-1, WARS, the guanylate-binding proteins $G B P 1, G B P 4$, and $G B P 5$ were identified.

Expression of $I D O-1$ was 4.29 -fold higher $(P=0.01$, $q=0.04$ ) and expression of WARS was 30.1-fold higher $(P=0.002, q=0.03)$ in medullary carcinoma compared with normal colon. Expression of several guanylate-binding protein genes (GBP1, GBP4, GBP5) were 10.35-23.39 fold higher in medullary carcinoma compared with normal colon $(P \leq 0.01$, $q \leq 0.04)$. Interferon gamma was expressed 1.38-fold higher in medullary carcinoma compared with adjacent normal colon $(P=0.04)$. PD-L1 $(C D 274)$ expression was increased 1.4-fold in medullary carcinoma, although not statistically significant $(P=0.08, q=0.1)$. PD-1 (PDCD1) expression overall was decreased in medullary carcinoma compared with normal colon, although not statistically significant $(P=0.89, q=0.5)$.

\section{The Cancer Genome Atlas Analysis}

Eight tumors morphologically consistent with medullary carcinoma were determined from the Cancer Genome Atlas data and were compared with 47 microsatellite unstable-high, 41 microsatellite unstable-low and 160 microsatellite stable colorectal carcinomas using the HiSeq data set. Gene set enrichment analysis of genomic data revealed several pathways enriched in medullary carcinoma compared with other microsatellite unstable tumors including PD-1 signaling $(P<0.0001)$, interferongamma signaling $(P<0.0001)$, and packaging of telomeres $(P<0.0001)$. A comparison of genes involved in the interferon-gamma pathway upregulated in medullary carcinoma compared with other microsatellite unstable and microsatellite stable tumors is summarized in Table 4. IDO-1 was upregulated 3.5-fold in medullary carcinoma compared with all other colorectal carcinomas $\left(P=9.8 \times 10^{-8}\right)$, 2.4-fold compared with microsatellite unstable- $\mathrm{H}$ colorectal carcinomas $(P=0.015)$, 3.1-fold compared with microsatellite unstable-L colorectal carcinomas $\left(P=1.6 \times 10^{-4}\right)$, and 3.8 -fold compared with microsatellite stable colorectal carcinomas $\left(P=1.6 \times 10^{-6}\right)$. Similarly, WARS, $G B P 1, G B P 4$, and GBP5 were upregulated in medullary carcinoma compared with all other groups. Interferon gamma was upregulated in medullary carcinoma compared with all groups although the effect was small compared with microsatellite unstable-High (fold change $0.8, P=0.14$ ). PD-1 (PDCD1) was upregulated in medullary carcinoma compared with all other groups and PD-L1 (CD274) was upregulated in medullary carcinoma compared with all groups except the microsatellite unstable-H category (fold change $0, P=0.98$ ).

Data comparing the same gene set among different categories of non-medullary microsatellite unstable tumors is summarized in Table 5. All eight genes were upregulated in microsatellite unstable tumors, with the greatest difference being between microsatellite unstable-high and microsatellite stable. $I D O-1$ was upregulated in microsatellite unstable vs microsatellite stable (1.5-fold change, $P=0.05)$, microsatellite unstable-high vs microsatellite stable (2.2-fold change, $P=0.0039$ ), and microsatellite unstable-high vs microsatellite unstable-low (1.8-fold change, $P=0.067)$. Among the guanylatebinding proteins, GBP5 showed the greatest difference between microsatellite unstable-high vs microsatellite stable (2.1-fold change, $P=0.00035$ ) and microsatellite unstable-high vs microsatellite unstable-low (2.1-fold change, $P=0.08$ ).

\section{Immunohistochemistry}

IDO-1, GBP5, and tRNA(trp) all showed a cytoplasmic and membranous staining pattern in tumor epithelial cells and surrounding stromal cells. PD-1, PD-L1, CD3, and CD8 all stained lymphocytes and 


\begin{tabular}{|c|c|c|c|c|c|c|c|c|c|c|c|c|}
\hline Gene symbol & $\begin{array}{l}\text { Fold change medullary } \\
\text { carcinoma vs all } \\
\text { colorectal carcinomas }\end{array}$ & $\mathrm{P}$-value & q-value & $\begin{array}{c}\text { Fold change medullary } \\
\text { carcinoma vs } \\
\text { microsatellite stable }\end{array}$ & P-value & $q$-value & $\begin{array}{l}\text { Fold change medullary } \\
\text { carcinoma vs } \\
\text { microsatellite } \\
\text { unstable-high }\end{array}$ & $\mathrm{P}$-value & q-value & $\begin{array}{l}\text { Id change medullary } \\
\text { carcinoma vs } \\
\text { microsatellite } \\
\text { unstable-low }\end{array}$ & $\mathrm{P}$-value & q-value \\
\hline IDO-1 & 3.5 & $9.8 \mathrm{E}-08$ & $9.7 \mathrm{E}-06$ & 3.8 & 1.6E-06 & $4.4 \mathrm{E}-05$ & 2.4 & $1.5 \mathrm{E}-02$ & $4.2 \mathrm{E}-01$ & 3.1 & 1.6E-04 & $2.8 \mathrm{E}-02$ \\
\hline WARS & 1.9 & 8.4E-08 & 8.4E-06 & 2.1 & $2.8 \mathrm{E}-07$ & $9.4 \mathrm{E}-06$ & 1.2 & 2.7E-03 & 2.9E-01 & 1.6 & $2.2 \mathrm{E}-06$ & $2.1 \mathrm{E}-03$ \\
\hline GBP1 & 1.7 & 3.2E-09 & $6.1 \mathrm{E}-07$ & 1.9 & $5.6 \mathrm{E}-15$ & $2.0 \mathrm{E}-12$ & 0.8 & 4.6E-02 & $5.2 \mathrm{E}-01$ & 1.3 & $5.3 \mathrm{E}-04$ & 5.3E-02 \\
\hline GBP4 & 2.4 & $9.9 \mathrm{E}-12$ & 4.1E-09 & 2.7 & $2.6 \mathrm{E}-13$ & $5.2 \mathrm{E}-11$ & 1.3 & $6.2 \mathrm{E}-03$ & $3.4 \mathrm{E}-01$ & 1.9 & 7.1E-06 & $4.0 \mathrm{E}-03$ \\
\hline GBP5 & 1.3 & $2.0 \mathrm{E}-01$ & 4.2E-01 & 1.9 & 8.8E-08 & $3.4 \mathrm{E}-06$ & -0.2 & $9.2 \mathrm{E}-01$ & 8.5E-01 & 0.6 & $6.8 \mathrm{E}-01$ & $8.4 \mathrm{E}-01$ \\
\hline$I F N G$ & 2.2 & $6.9 \mathrm{E}-08$ & $7.4 \mathrm{E}-06$ & 2.8 & $1.8 \mathrm{E}-16$ & 8.5E-14 & 0.8 & $1.4 \mathrm{E}-01$ & $6.9 \mathrm{E}-01$ & 1.5 & $3.5 \mathrm{E}-03$ & $1.4 \mathrm{E}-01$ \\
\hline$P D-L 1$ (CD274) & 1.3 & 4.2E-02 & $1.9 \mathrm{E}-01$ & 1.8 & 2.7E-06 & 6.7E-05 & 0.0 & $9.8 \mathrm{E}-01$ & 8.6E-01 & 0.6 & $4.4 \mathrm{E}-01$ & $8.1 \mathrm{E}-01$ \\
\hline$P D-1(P D C D 1)$ & 1.4 & 3.3E-03 & 4.1E-02 & 1.8 & 3.5E-09 & 2.1E-07 & 0.5 & $4.8 \mathrm{E}-01$ & 8.1E-01 & 0.8 & $1.9 \mathrm{E}-01$ & 7.2E-01 \\
\hline
\end{tabular}

Medullary carcinoma had significant upregulation of several IFN $\gamma$-inducible genes compared with other microsatellite unstable tumors including IDO-1, WARS, GBP1, and GBP4.

Table 5 Evaluation of The Cancer Genome Atlas HiSeq microsatellite unstable tumors

\begin{tabular}{|c|c|c|c|c|c|c|c|c|c|}
\hline Gene symbol & $\begin{array}{l}\text { Fold change } \\
\text { microsatellite unstable } \\
\text { vs microsatellite stable }\end{array}$ & P-value & q-value & $\begin{array}{c}\text { Fold change microsatellite } \\
\text { unstable-high vs } \\
\text { microsatellite stable }\end{array}$ & P-value & q-value & $\begin{array}{c}\text { Fold change } \\
\text { microsatellite unstable- } \\
\text { high vs microsatellite } \\
\text { unstable-low }\end{array}$ & P-value & q-value \\
\hline$I D O-1$ & 1.5 & $5.0 \mathrm{E}-02$ & 7.0E-02 & 2.2 & 3.9E-03 & 4.4E-03 & 1.8 & 6.7E-02 & 8.7E-02 \\
\hline WARS & 0.7 & $4.2 \mathrm{E}-03$ & $1.2 \mathrm{E}-02$ & 1.2 & 1.4E-05 & 3.5E-05 & 1.1 & $6.8 \mathrm{E}-04$ & $2.8 \mathrm{E}-03$ \\
\hline$G B P 1$ & 0.8 & $2.0 \mathrm{E}-06$ & $3.8 \mathrm{E}-05$ & 1.3 & $2.0 \mathrm{E}-12$ & $3.8 \mathrm{E}-11$ & 1.2 & $3.8 \mathrm{E}-04$ & $1.7 \mathrm{E}-03$ \\
\hline GBP4 & 1.1 & 8.1E-05 & $5.9 \mathrm{E}-04$ & 1.8 & 1.7E-09 & 1.3E-08 & 1.7 & $1.4 \mathrm{E}-04$ & 8.3E-04 \\
\hline GBP5 & 1.4 & 1.0E-02 & 2.3E-02 & 2.1 & 3.5E-04 & $5.7 \mathrm{E}-04$ & 2.1 & 8.3E-02 & $1.0 \mathrm{E}-01$ \\
\hline$I F N G$ & 1.5 & $8.0 \mathrm{E}-07$ & 1.9E-05 & 2.2 & 1.1E-12 & $2.4 \mathrm{E}-11$ & 2.0 & $4.1 \mathrm{E}-04$ & $1.9 \mathrm{E}-03$ \\
\hline$P D-L 1(C D 274)$ & 1.2 & 2.5E-04 & 1.4E-03 & 1.7 & 4.4E-07 & $1.8 \mathrm{E}-06$ & 1.6 & 1.8E-02 & $3.4 \mathrm{E}-02$ \\
\hline$P D-1(P D C D 1)$ & 1.0 & 3.3E-05 & 3.0E-04 & 1.4 & 1.2E-07 & $5.8 \mathrm{E}-07$ & 0.8 & 1.3E-01 & $1.4 \mathrm{E}-01$ \\
\hline
\end{tabular}

As a group, microsatellite unstable tumors showed upregulation of all eight IFN $\gamma$-inducible genes with greatest differences seen with IDO-1, WARS, and GBP5. 
PD-L1-stained tumor epithelium in a cytoplasmic pattern. Foxp3-stained lymphocytic nuclei. The staining results are summarized in Figure 1 and representative images are depicted in Figure 2 . Consistent with the gene expression analysis and The Cancer Genome Atlas data, medullary carcinoma showed epithelial overexpression of IDO-1, tRNA(trp), and GBP5. Epithelial IDO-1 was overexpressed in $>50 \%$ of tumor cells (score 3 ) in $\sim 29 \%(30 / 104)$ of medullary carcinomas, $4 \%(2 / 47)$ of poorly differentiated, and no cases of both microsatellite unstable and microsatellite stable well-differentiated carcinomas $(P<0.0001)$. Epithelial tRNA(trp) was overexpressed in $>50 \%$ of tumor cells in $81 \%(84 / 104)$ of medullary carcinoma, $19 \%$ (9/47) of poorly differentiated colorectal carcinomas, $32 \%(7 / 22)$ of microsatellite unstable well differentiated, and $3 \%(1 / 30)$ of microsatellite stable well differentiated $(P \leq 0.0002)$. Epithelial GBP5 was overexpressed in $>50 \%$ of tumor cells in $\sim 17 \%(18 / 104)$ of medullary carcinoma, $2 \% \quad(1 / 47)$ of poorly differentiated colorectal carcinomas, and no cases of microsatellite unstable well differentiated and microsatellite stable well differentiated $(P<0.0089)$. Epithelial PD-L1 overexpression in $>50 \%$ of tumor cells was similar between medullary carcinomas $(18 \%, 19 / 104)$ and microsatellite unstable well-differentiated $(23 \%, 5 / 22)$ as well as between poorly differentiated colorectal carcinomas (9\%, $4 / 47)$ and microsatellite stable well-differentiated $(10 \%, 3 / 30)$, although not statistically significant $(P=0.5)$. A subgroup analysis comparing expression of IDO-1, tRNA(trp), GBP5, and PD-L1 between both microsatellite stable $(n=28)$ and microsatellite unstable $(n=19)$ poorly differentiated carcinomas revealed no statistically significant differences.

Tumor stromal staining for IDO-1 and GBP5 were similar for medullary carcinoma and microsatellite unstable well differentiated. IDO-1 overexpression was present in $>50 \%$ of stromal cells (score 2) in $\sim 17 \%(18 / 102)$ of medullary carcinoma and $36 \%$ $(8 / 22)$ of microsatellite unstable well differentiated, compared with $13 \%$ (6/47) of poorly differentiated colorectal carcinomas and $3 \%(1 / 30)$ of microsatellite stable well differentiated $(P=0.002)$. GBP5 overexpression was present in $>50 \%$ of stromal cells (score 2) in $\sim 48 \%(50 / 104)$ of medullary carcinoma and $36 \%(8 / 22)$ of microsatellite unstable well-differentiated, compared with $15 \%$ (7/47) of poorly differentiated colorectal carcinomas and no cases of microsatellite stable well differentiated $(P<0.0001)$. There were no appreciable differences in tRNA(trp) staining of stroma across all four categories of tumor.

Absolute and mean counts for tumor intraepithelial and stromal lymphocytes are summarized in Figure 3 and Table 6. Mean intraepithelial CD8+, PD-1+, PD-L1+, and Foxp3+ lymphocyte counts were higher in medullary carcinoma compared with all other groups. Medullary carcinoma contained statistically significant higher mean CD8+ intraepithelial lymphocytes per core $($ mean $=129)$ and Foxp3+ intraepithelial lymphocytes compared with the microsatellite unstable well-differentiated category $(P<0.0001)$. Only three cases of medullary carcinoma contained a significantly lower amount of CD8+ intraepithelial tumor-infiltrating lymphocytes (mean =17). Mean stromal PD-1+ and Foxp3+ lymphocytes were highest in the microsatellite unstable well-differentiated group. A subgroup analysis comparing expression of these lymphocyte markers between both microsatellite stable $(n=28)$ and microsatellite unstable $(n=19)$ poorly differentiated carcinomas revealed no statistically significant differences.

In a $\chi^{2} 1: 1$ analysis, several of the epithelial and lymphocyte markers showed positive correlation. Across all categories, IDO-1 epithelial staining positively correlated with tRNA(trp) epithelial staining $(P<0.0001)$, GBP5 epithelial and stromal staining $(P<0.0001, \quad P=0.0002)$, PD-L1+ tumorinfiltrating lymphocytes $(P<0.0001)$, Foxp3+ intraepithelial lymphocytes $(P<0.0001)$, and CD8+ tumor epithelial and stromal lymphocytes $(P<0.0001)$. Within medullary carcinomas alone, several markers were positively correlated as well. IDO-1 epithelial staining strongly correlated with tRNA(trp) epithelial staining and GBP5 epithelial and stromal staining $(P=0.005)$. IDO-1 stromal staining positively correlated with intraepithelial PD-1+ lymphocytes $(P=0.017)$ and CD8+ tumor-infiltrating lymphocytes $(P=0.0084)$. tRNA(trp) correlated strongly with GBP epithelial overexpression $(P=0.04)$ and PD-L1 epithelial overexpression $(P=0.04)$. PD- $1+$ intraepithelial lymphocytes correlated with the presence of PD-L1+ tumor-infiltrating lymphocytes $(P=0.0058)$, Foxp3+ intraepithelial lymphocytes $(P=0.0079)$, and Foxp3+ stromal lymphocytes $(P=0.025)$. Finally, the presence of CD8+ intraepithelial lymphocytes correlated with PD-L1+ intraepithelial lymphocytes $(P=0.0021)$, Foxp3+ intraepithelial lymphocytes $(P=0.0149)$, and PD-1 intraepithelial lymphocytes $(P=0.0007)$.

\section{Discussion}

The tumor immune microenvironment in cancer is emerging as an increasingly important component of our understanding of host-tumor interactions with implications for therapeutic intervention. Microsatellite unstable colorectal carcinomas are well known to elicit a host immune response that may impart a more favorable prognosis, yet these cancers still progress. Evidence suggests that the immune response may be impaired by upregulation of multiple checkpoint inhibitors and that these inhibitory pathways are upregulated in microsatellite unstable colorectal carcinomas. ${ }^{18,27-29}$ Most of these studies, however, classify microsatellite unstable colorectal carcinomas as a single group and do not consider the histologic heterogeneity of microsatellite unstable colorectal carcinomas. As such, we hypothesized 
IDO-1 epithelial staining

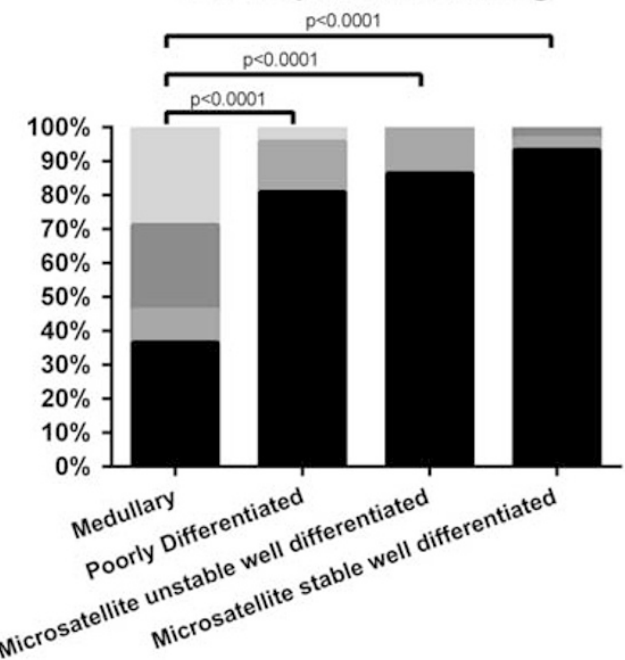

WARS epithelial staining
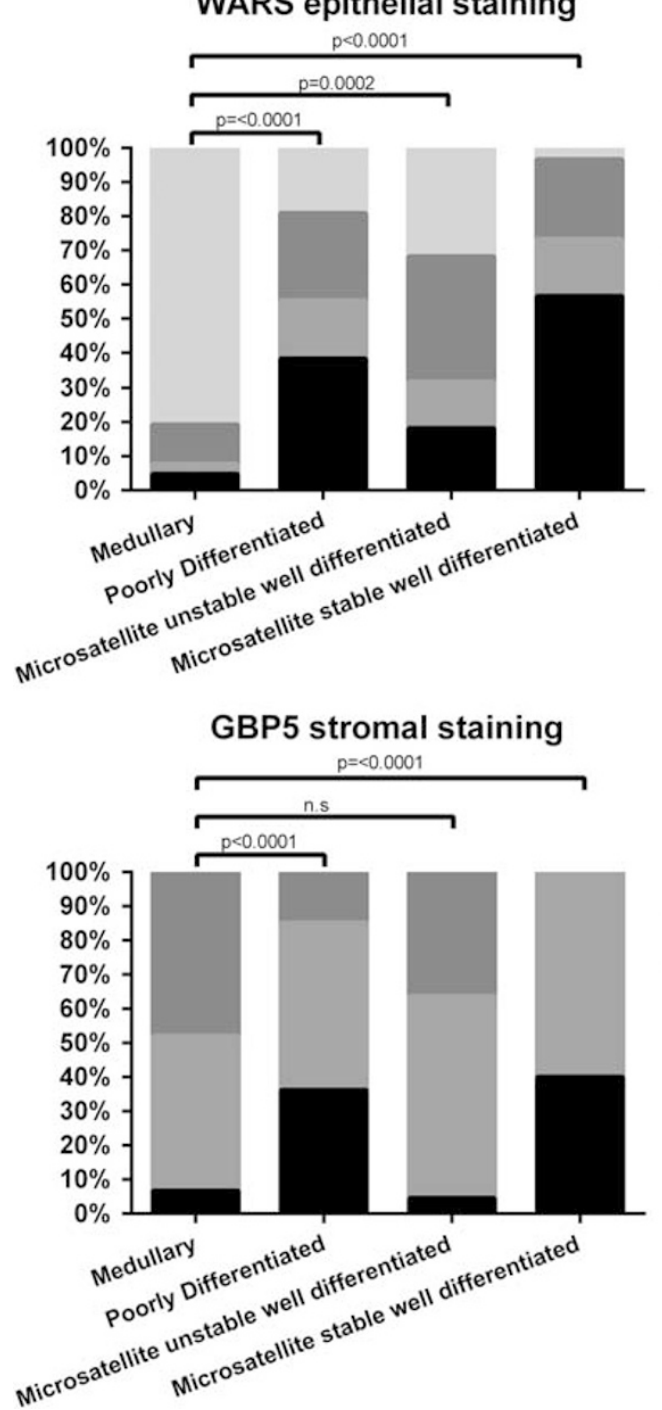

IDO-1 stromal staining

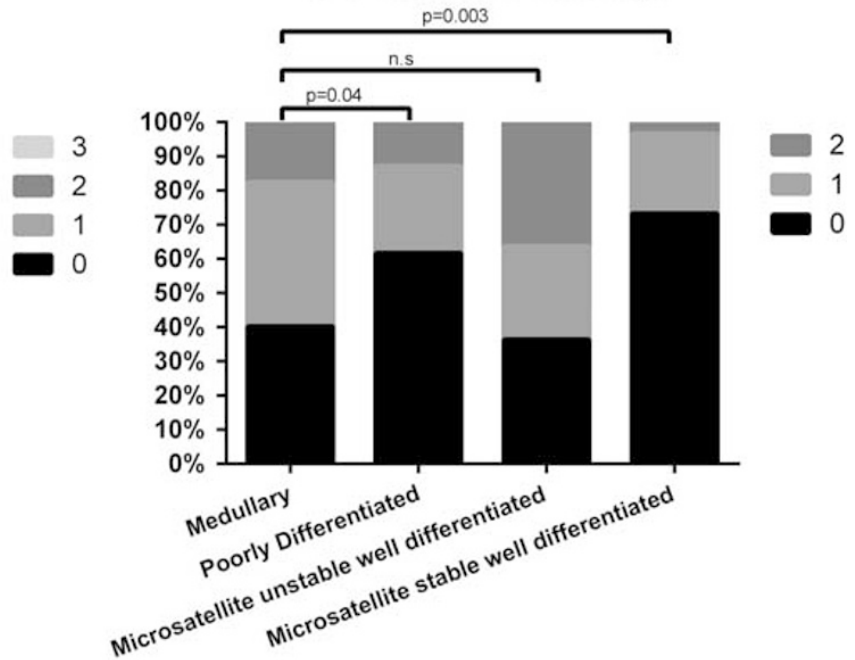

\section{GBP5 epithelial staining}

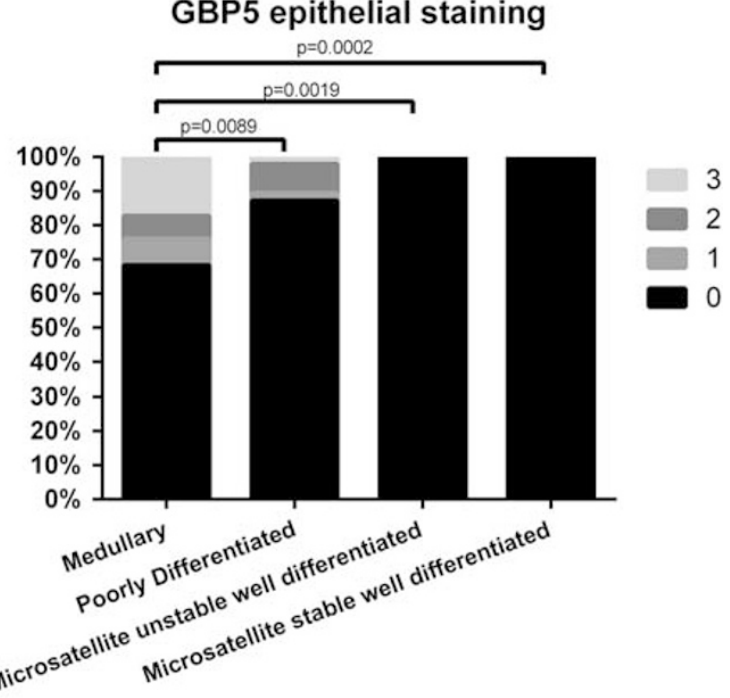

\section{PD-L1 epithelial staining}

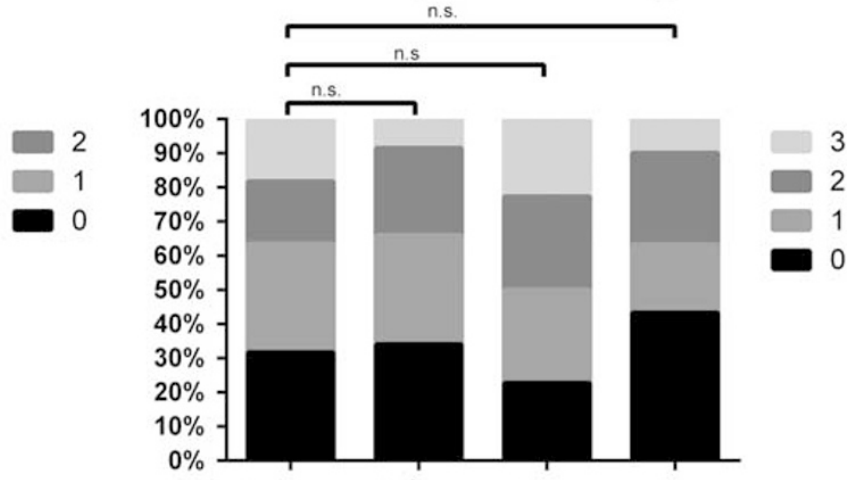

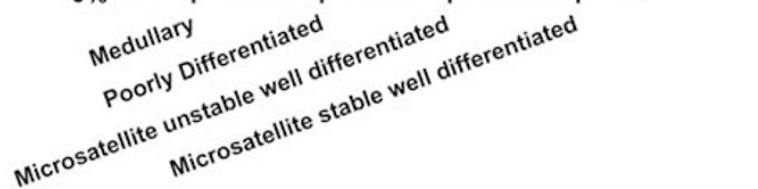

Figure 1 Percentage of cases by histologic subtype demonstrating epithelial and stromal staining for IDO-1, tRNA(trp) or WARS, GBP5, and PD-L1. Scores based on percent of tumor epithelium or stromal cells with moderate-intense staining as follows: epithelium $(0=0 \%$; $1=<25 \% ; 2=25-50 \% ; 3=>50 \%)$; stroma $(0=0 \%, 1=0-50 \%, 2=>50 \%)$. 

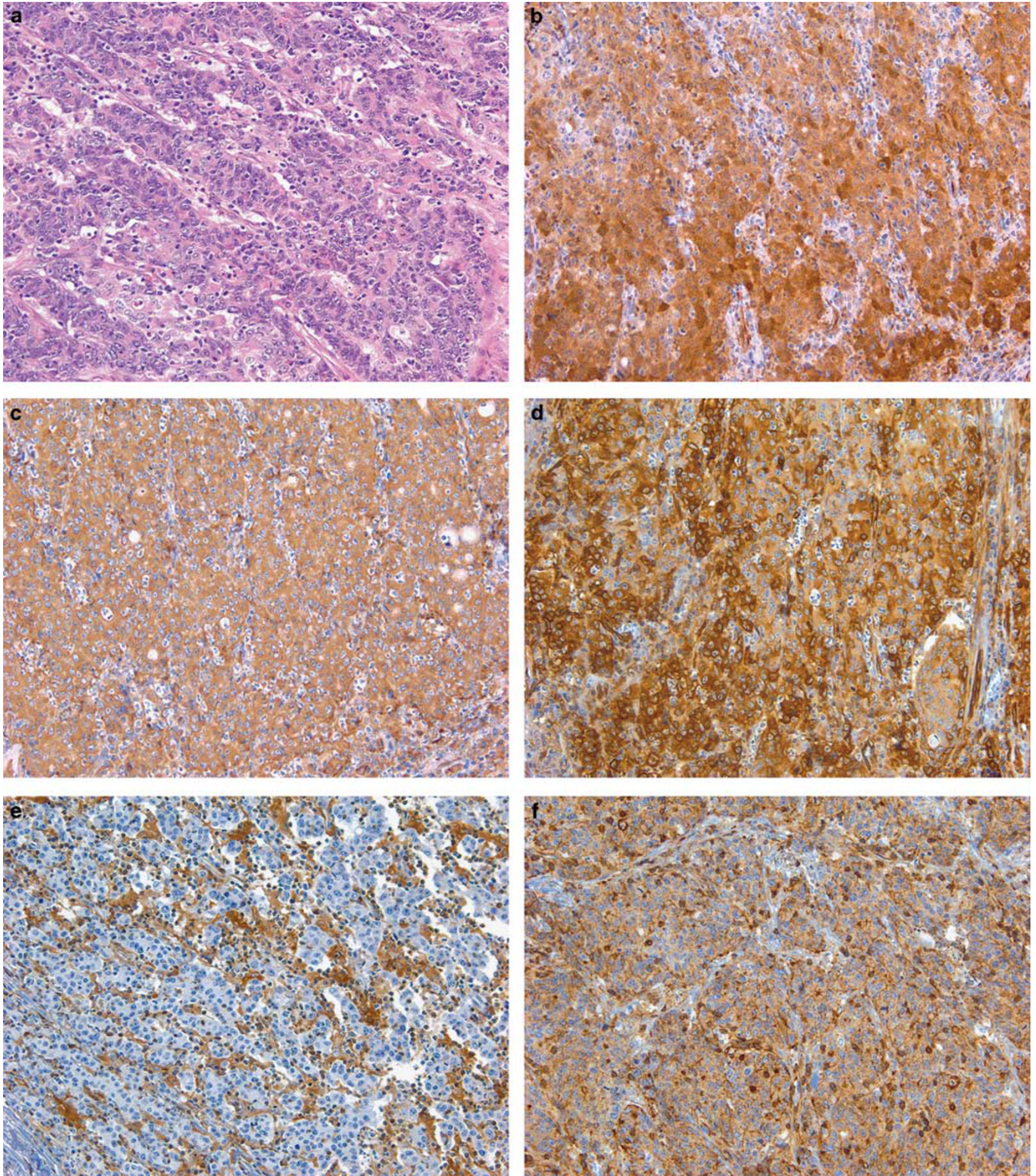

Figure 2 (a) Medullary carcinoma H\&E $(20 \times)$; (b) 3+ IDO-1 epithelial staining in medullary carcinoma; (c) 3+ tRNA(trp) or WARS staining in medullary carcinoma; (d) 3+ GBP5 staining in medullary carcinoma; (e) 2+ GBP5 stromal staining in medullary carcinoma; (f) 3+ PD-L1 staining in medullary carcinoma with numerous PD-L1+ tumor-infiltrating lymphocytes. All images are from the same case.

immune regulatory pathways may be particularly upregulated in medullary carcinoma because it represents the most specific histologic indicator of a microsatellite unstable colorectal carcinoma, ${ }^{30}$ owing to its distinct morphology. Using a combination of gene expression analysis, curated Cancer Genome Atlas genomic data, and immunohistochemical analysis of a large cohort of medullary carcinoma, we demonstrate that medullary carcinoma has a unique immune microenvironment 
PD-1+ epithelial lymphocytes

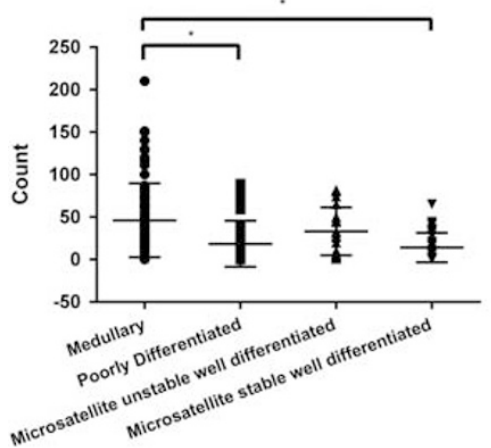

Foxp3+ epithelial lymphocytes

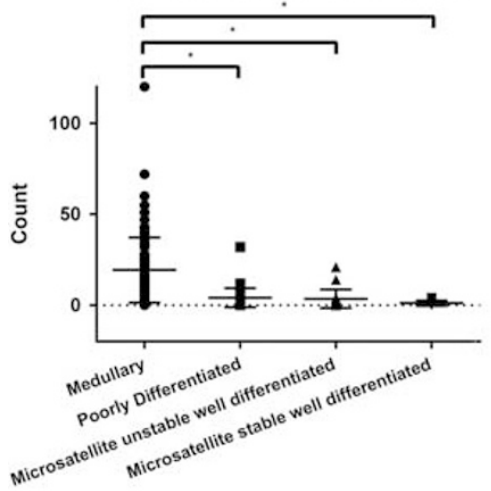

CD8+ epithelial lymphocytes

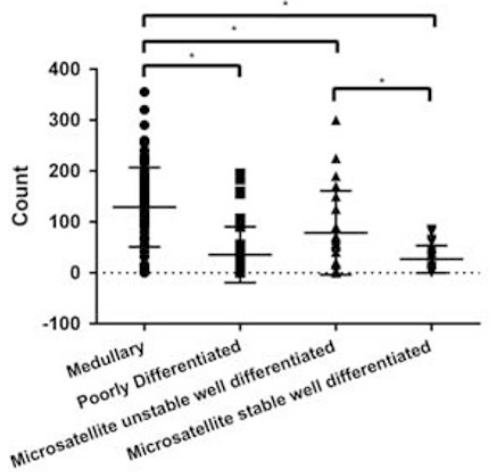

PD-1+ stromal lymphocytes

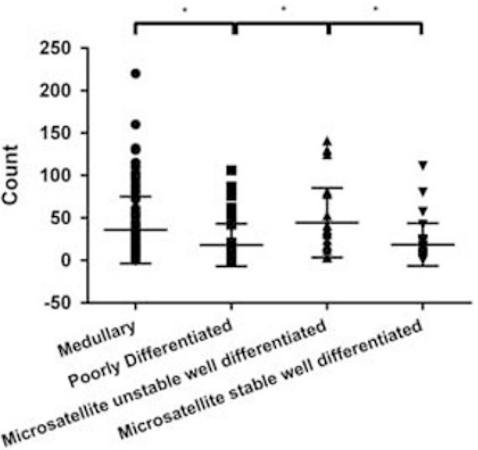

Foxp3+ stromal lymphocytes

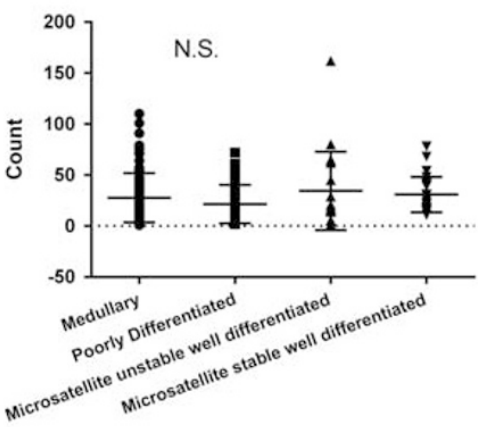

CD8+ stromal lymphocytes

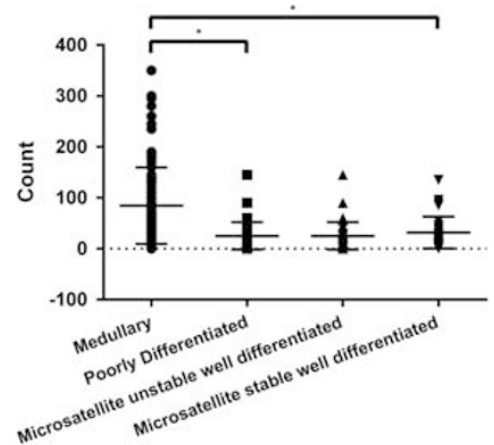

PD-L1+ epithelial lymphocytes

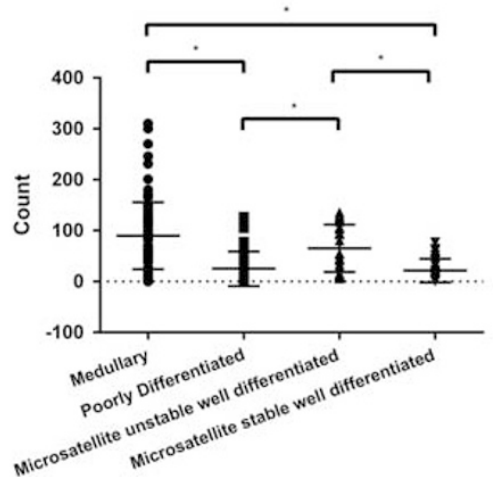

Figure 3 Scatterplot of tumor-infiltrating lymphocytes positive for CD8, PD-1, PD-L1, and Foxp3 with means and s.d. Significant differences were observed between PD-1+, PD-L1+, CD8+, and Foxp3+ tumor-infiltrating lymphocytes between medullary carcinoma and poorly differentiated carcinomas. CD8+ and Foxp3+ tumor-infiltrating lymphocytes were significantly increased in medullary carcinoma compared with other microsatellite unstable tumors. Asterisk $\left({ }^{*}\right)$ indicates $P<0.0001$. 
Table 6 Mean lymphocyte counts averaged per tissue microarray core by immunohistochemistry for each tumor subtype

\begin{tabular}{|c|c|c|c|c|c|c|c|}
\hline & $\begin{array}{c}P D-1 \\
\text { epithelium }\end{array}$ & $\begin{array}{l}P D-1 \\
\text { stroma }\end{array}$ & $\begin{array}{l}\text { PD-L1 } \\
\text { epithelium }\end{array}$ & $\begin{array}{l}\text { Foxp3 } \\
\text { epithelium }\end{array}$ & $\begin{array}{l}\text { Foxp3 } \\
\text { stroma }\end{array}$ & $\begin{array}{c}\text { CD8 } \\
\text { epithelium }\end{array}$ & $\begin{array}{l}\text { CD8 } \\
\text { stroma }\end{array}$ \\
\hline Medullary carcinoma & 46 & 36 & 90 & 19 & 28 & 129 & 85 \\
\hline Poorly differentiated & 18 & 18 & 25 & 4 & 21 & 36 & 26 \\
\hline $\begin{array}{l}\text { Microsatellite unstable } \\
\text { well differentiated }\end{array}$ & 33 & 44 & 65 & 4 & 34 & 79 & 60 \\
\hline $\begin{array}{l}\text { Microsatellite stable well } \\
\text { differentiated }\end{array}$ & 14 & 19 & 21 & 1 & 31 & 27 & 32 \\
\hline
\end{tabular}

similar, but distinct enough from other microsatellite unstable colorectal carcinomas that may have important biological and therapeutic implications.

We observed that the immune microenvironment of medullary carcinoma contains a profound antitumor immune phenotype, with the presence of numerous CD8+ cytotoxic T cells and IFN $\gamma$ upregulated genes. Higher mean CD8+ tumor-infiltrating lymphocytes were present in both the epithelial and stromal compartments in medullary carcinoma compared with microsatellite unstable and microsatellite stable tumors. These CD8+ tumor-infiltrating lymphocytes are presumed to be stimulated by 'neoantigen' production by microsatellite unstable tumors, which carry mutations at rates 10-50 times higher than microsatellite stable tumors., ${ }^{3,31}$ CD8+ tumor-infiltrating lymphocytes are activated upon presentation of these antigens, secrete various pro-inflammatory cytokines, and in general have been associated with a better prognosis. ${ }^{32}$ These CD8 + tumor-infiltrating lymphocytes promote a strong IFN $\gamma$ response and some of these gene products may also account for the more favorable outcomes of microsatellite unstable colorectal carcinomas. For example, the GBPs are members of the guanosine triphosphatase family (GTPases) that are induced by IFN $\gamma$ and have a role in resistance to pathogens among other functions. ${ }^{33}$ In colorectal cancer, GBP1 overexpression in tumor stroma inhibits tumor growth and correlates with improved survival. ${ }^{34,35}$ The functions of other GBPs are less clear although animal and in-vitro models suggest a protective role in controlling infection and autoimmunity as GBPs are essential for formation of the inflammasome complex. ${ }^{36}$ The inflammasome complex promotes inflammatory cell death through activation of cysteine protease caspase- 1 and is purported to have tumor suppressive effects in some studies. ${ }^{37}$ Our finding of upregulated GBP1, GBP4, and GBP5 in medullary carcinoma compared with all other colorectal carcinomas including microsatellite unstable colorectal carcinomas suggests a possible mechanistic link between the pro-inflammatory microenvironment and observed more favorable clinical outcomes in microsatellite unstable colorectal carcinomas.

Our analysis showed that despite the presence of the cytotoxic T-cell phenotype, immune inhibitory pathways were active in medullary carcinoma. Gene expression analysis of PD-1 (PDCD1) in our medullary carcinoma and in the Cancer Genome Atlas cohorts showed upregulation, with immunohistochemical analysis of 105 medullary carcinomas confirming higher mean PD-1+ tumor-infiltrating lymphocytes within epithelium compared with other microsatellite unstable tumors. The major role of PD-1 is to reduce activity of T cells during an inflammatory response by inhibiting kinases that are involved in T-cell activation, and its expression is induced when $\mathrm{T}$ cells become activated.13,38,39 Increased PD-1 expression on tumor-infiltrating lymphocytes is seen in a variety of tumor types, ${ }^{40}$ including microsatellite unstable colorectal carcinomas. ${ }^{10,12}$ Similarly, the PD-1 ligand (PD-L1, CD274) is often upregulated on the tumor cell surface and tumor-infiltrating lymphocytes from many different tumors. ${ }^{15,41}$ In our immunohistochemical analysis mean intraepithelial PD-L1+ tumor-infiltrating lymphocytes were higher in medullary carcinoma compared with microsatellite unstable and microsatellite stable colorectal carcinomas. In normal physiology, PD-L1 expression can be induced by IFN $\gamma$ as a means to protect tissues from infection-induced immune-mediated damage, ${ }^{42,43}$ but in tumors enriched with an IFN $\gamma$ microenvironment, such as microsatellite unstable tumors, the same mechanism may possibly be exploited as a means of antitumor immune escape. There is also evidence that PD-L1 expression can be driven by oncogenic signaling pathways as is the case with PTEN deletion in glioblastomas ${ }^{44}$ and constitutive anaplastic lymphoma kinase signaling in lung cancers, which drive PD-L1 expression through signal transducer and activator 3 (STAT3) signaling. ${ }^{45}$ PTEN deletions are often seen in microsatellite unstable colorectal carcinoma ${ }^{46}$ and STAT3 overexpression was observed in our initial gene expression analysis (Supplementary data). Interestingly, in our immunohistochemical analysis, epithelial tumor cell expression of PD-L1 was similar across all categories with a slight statistically non-significant increase in epithelial staining of medullary carcinoma and microsatellite unstable tumors. The significance of this is not entirely clear as epithelial PD-L1 overexpression is seen in many tumor types. ${ }^{47-49}$ In addition, a recent Phase I clinical trial of an anti-PD-L1 antibody (MPDL3280A) showed that PD-L1+ tumor-infiltrating lymphocytes were a better predictor of response to treatment 
$(P=0.007)$ than PD-L1 expression on tumor cells $(P=0.079){ }^{50}$ This association underscores that epithelial expression of PD-L1 may not be entirely predictive of response, and our data support that PD-L1 expression on tumor-infiltrating lymphocytes may be of greater biological importance. Finally, we show that mean intraepithelial $\mathrm{T}$ regulatory cells were also highly increased in medullary carcinoma compared with all other colorectal carcinomas. T regulatory cells are upregulated in a variety of tumors and dampen T-cell responses to tumor associated antigens. ${ }^{51} \mathrm{PD}-1$ is also highly expressed on T regulatory cells and can promote their proliferation, further downregulating the immune response. ${ }^{52}$

We provide evidence that in addition to proteinligand interactions as a mechanism of immune escape, immunomodulatory metabolic pathways are upregulated in medullary carcinoma. IDO-1 is an intracellular enzyme that degrades tryptophan (Trp) to kynurenine. Two paralogs exist, IDO-1 and IDO-2; however, the function of IDO-2 is less clear because of its very low Trp degradation activity. ${ }^{53}$ The depletion of Trp in the tumor microenvironment and production of Trp metabolites leads to inhibition of T-cell responses characterized by reduced proliferation, increased apoptosis and differentiation of naive $\mathrm{T}$ cells into T regulatory cells. ${ }^{54,55}$ IDO-1 overexpression has been described in several tumors, including colorectal carcinomas, and is thought to contribute to their evasion from the host immune system. ${ }^{56-58}$ Our analysis of IDO-1 in medullary carcinoma showed a 2.4-fold increase in expression compared with microsatellite unstable-High colorectal carcinomas from the Cancer Genome Atlas data and immunohistochemical analysis showed that tumor cells were positive for IDO-1 in $64 \%$ of medullary carcinomas, with $~ 30 \%$ of cases showing a majority of tumor cells with moderate-strong staining. This is in contrast to $86 \%$ of the microsatellite unstable well-differentiated and $81 \%$ of poorly differentiated carcinomas with absent epithelial staining, highlighting the unique upregulation of this pathway in medullary carcinoma. In keeping with these findings, clinical trials are currently underway for competitive IDO inhibitors. ${ }^{59,60}$ Logically, Trp depletion from the tumor microenvironment should impair protein synthesis in neoplastic cells. However, IDO-1-expressing cells may be protected from Trp self-starvation by increasing the expression of tryptophanyl-tRNA-synthetase (tRNA(trp) or WARS). ${ }^{61}$ This Trp-tRNA complex would protect Trp from IDO-mediated degradation and make it available for protein synthesis. Indeed, we show evidence that this self-protective pathway is more prevalent in medullary carcinoma compared with all other tumors, with $81 \%$ of medullary carcinoma showing expression in $>50 \%$ of tumor cells, compared with $20 \%$ of poorly differentiated colorectal carcinomas, $32 \%$ of microsatellite unstable well-differentiated, and $3 \%$ of microsatellite stable well-differentiated colorectal carcinomas. In addition, we show a strong correlation between IDO-1 tumor cell expression and tRNA(trp) expression. Interestingly, tRNA(trp) expression has been associated with improved survival and decreased risk of recurrence in CRC in at least one study, although microsatellite unstable tumors were not specifically analyzed. ${ }^{62}$

Medullary carcinomas and poorly differentiated carcinoma often show morphologic overlap and cases of medullary carcinoma are occasionally misclassified on retrospective review even after the recognition of medullary carcinoma as a distinct subset of CRC. ${ }^{6}$ Despite sometimes similar morphology, medullary carcinoma has a distinct tumor immune microenvironment. The greatest differences were seen with IDO-1 epithelial expression $(64 \%$ of medullary carcinoma vs 19\% of poorly differentiated tumors), tRNA(trp) epithelial expression (81\% of medullary carcinoma vs 19\% of poorly differentiated tumors), CD8+, and PD-L1+ tumor-infiltrating lymphocytes. These differences may be useful in differentiating between the two if morphologic and/ or immunohistochemical features are equivocal. Interestingly, three cases of medullary carcinoma had significantly lower average intraepithelial tumor-infiltrating lymphocytes compared with the rest of the group. Although this may represent inadequate tumor sampling using tissue microarray, all three cases showed 1-2+ positive IDO-1 and GBP5 staining, and 3+ tRNA(trp) staining, indicating upregulation of these markers despite less tumorinfiltrating lymphocytes in the immediate vicinity.

To the best of our knowledge, this study represents the only study specifically addressing the tumor immune microenvironment in medullary carcinoma separate from other microsatellite unstable-high colorectal carcinomas and is also the largest accumulation of medullary carcinoma in a single study reported thus far. We applied strict morphologic criteria to define medullary carcinoma and showed that upregulation of immune-mediated pathways was consistent between the initial gene expression array, the Cancer Genome Atlas data and immunohistochemical analysis. One of the limitations of the study includes the initial comparison of medullary carcinoma with adjacent normal epithelium in the original RIH expression array. The epithelial population was likely purer in the normal epithelium compared with tumor owing to the presence of numerous tumor-infiltrating lymphocytes. Nonetheless, we were able to parse out these differences in the immunohistochemical analysis, which showed significant differences between epithelial and TIL expression.

\section{Conclusion}

We have shown that the tumor immune microenvironment of medullary carcinoma represents a complex balance between a pro-inflammatory antitumor response and immune regulation via checkpoint inhibition. These pathways are more prevalent 
in medullary carcinoma compared with other microsatellite unstable colorectal carcinomas. The potential therapeutic implications may be far-reaching, given recent preliminary evidence that anti-PD-L1 therapy is beneficial in patients with microsatellite unstable colorectal carcinomas. ${ }^{18}$

\section{Acknowledgments}

Research reported in this publication was supported by the Molecular Pathology Core of the COBRE Center for Cancer Research Development, funded by the National Institute of General Medical Sciences of the National Institutes of Health under Award Number P20GM103421.

\section{Disclosure/conflict of interest}

The authors declare no conflict of interest.

\section{References}

1 Gajewski TF, Schreiber H, Fu YX. Innate and adaptive immune cells in the tumor microenvironment. Nat Immunol 2013;14:1014-1022.

2 Alexander J, Watanabe T, Wu TT et al. Histopathological identification of colon cancer with microsatellite instability. Am J Pathol 2001;158:527-535.

3 Tougeron D, Fauquembergue E, Rouquette A et al. Tumor-infiltrating lymphocytes in colorectal cancers with microsatellite instability are correlated with the number and spectrum of frameshift mutations. Mod Pathol 2009;22:1186-1195.

4 Popat S, Hubner R, Houlston RS. Systematic review of microsatellite instability and colorectal cancer prognosis. J Clin Oncol 2005;23:609-618.

5 Guastadisegni C, Colafranceschi M, Ottini L et al. Microsatellite instability as a marker of prognosis and response to therapy: a meta-analysis of colorectal cancer survival data. Eur J Cancer 2010;46:2788-2798.

6 Lanza G, Gafa R, Matteuzzi M et al. Medullary-type poorly differentiated adenocarcinoma of the large bowel: a distinct clinicopathologic entity characterized by microsatellite instability and improved survival. J Clin Oncol 1999;17:2429-2438.

7 Ruschoff J, Dietmaier W, Luttges J et al. Poorly differentiated colonic adenocarcinoma, medullary type: clinical, phenotypic, and molecular characteristics. Am J Pathol 1997;150:1815-1825.

8 Thirunavukarasu P, Sathaiah M, Singla S et al. Medullary carcinoma of the large intestine: a population based analysis. Int J Oncol 2010;37:901-907.

9 Wick MR, Vitsky JL, Ritter JH et al. Sporadic medullary carcinoma of the colon: a clinicopathologic comparison with nonhereditary poorly differentiated enteric-type adenocarcinoma and neuroendocrine colorectal carcinoma. Am J Clin Pathol 2005;123:56-65.

10 Galon J, Costes A, Sanchez-Cabo F et al. Type, density, and location of immune cells within human colorectal tumors predict clinical outcome. Science 2006;313: 1960-1964.
11 Boissiere-Michot F, Lazennec G, Frugier $\mathrm{H}$ et al. Characterization of an adaptive immune response in microsatellite-instable colorectal cancer. Oncoimmunology 2014;3:e29256.

12 Llosa NJ, Cruise M, Tam A et al. The vigorous immune microenvironment of microsatellite instable colon cancer is balanced by multiple counter-inhibitory checkpoints. Cancer Discov 2015;5:43-51.

13 Freeman GJ, Long AJ, Iwai Y et al. Engagement of the PD-1 immunoinhibitory receptor by a novel B7 family member leads to negative regulation of lymphocyte activation. J Exp Med 2000;192:1027-1034.

14 Keir ME, Butte MJ, Freeman GJ et al. PD-1 and its ligands in tolerance and immunity. Annu Rev Immunol 2008;26:677-704.

15 Zou W, Chen L. Inhibitory B7-family molecules in the tumour microenvironment. Nat Rev Immunol 2008;8: $467-477$.

16 Hirano F, Kaneko K, Tamura $\mathrm{H}$ et al. Blockade of B7-H1 and PD-1 by monoclonal antibodies potentiates cancer therapeutic immunity. Cancer Res 2005;65: 1089-1096.

17 Angelova M, Charoentong P, Hackl H et al. Characterization of the immunophenotypes and antigenomes of colorectal cancers reveals distinct tumor escape mechanisms and novel targets for immunotherapy. Genome Biol 2015;16:64.

18 Le DT, Uram JN, Wang H et al. PD-1 blockade in tumors with mismatch-repair deficiency. $N$ Engl J Med 2015;372:2509-2520.

19 Knox RD, Luey N, Sioson L et al. Medullary colorectal carcinoma revisited: a clinical and pathological study of 102 cases. Ann Surg Oncol 2015;22:2988-2996.

20 Bosman FT, Carneiro F, Hruban RH et al. WHO classification of tumours of the digestive system. 4th edn, IARC: Lyon, France, 2010, pp 138.

21 Irizarry RA, Hobbs B, Collin F et al. Exploration, normalization, and summaries of high density oligonucleotide array probe level data. Biostatistics 2003;4: 249-264.

22 Storey JD, Tibshirani R. Statistical significance for genomewide studies. Proc Natl Acad Sci USA 2003;100:9440-9445.

23 Ashburner M, Ball CA, Blake JA et al. Gene ontology: tool for the unification of biology. The Gene Ontology Consortium. Nat Genet 2000;25:25-29.

24 Subramanian A, Tamayo P, Mootha VK et al. Gene set enrichment analysis: a knowledge-based approach for interpreting genome-wide expression profiles. Proc Natl Acad Sci USA 2005;102:15545-15550.

25 Gao J, Aksoy BA, Dogrusoz U et al. Integrative analysis of complex cancer genomics and clinical profiles using the cBioPortal. Sci Signal 2013;6:pl1.

26 Broad Institute TCGA Genome Data Analysis Center (2015): Analysis-ready standardized TCGA data from Broad GDAC Firehose stddata_2015_06_01 run. Broad Institute of MIT and Harvard. Dataset. [Internet]. Available from http://dx.doi.org/10.7908/C1251HBG.

27 Platten M, von Knebel Doeberitz N, Oezen I et al. Cancer immunotherapy by targeting IDO1/TDO and their downstream effectors. Front Immunol 2015;5:673.

28 Takamatsu M, Hirata A, Ohtaki $\mathrm{H}$ et al. Inhibition of indoleamine 2,3-dioxygenase 1 expression alters immune response in colon tumor microenvironment in mice. Cancer Sci 2015;106:1008-1015.

29 Zhai L, Spranger S, Binder DC et al. Molecular pathways: targeting IDO1 and other tryptophan 
dioxygenases for cancer immunotherapy. Clin Cancer Res 2015;21:5427-5433.

30 Shia J, Ellis NA, Paty PB et al. Value of histopathology in predicting microsatellite instability in hereditary nonpolyposis colorectal cancer and sporadic colorectal cancer. Am J Surg Pathol 2003;27:1407-1417.

31 Howitt BE, Shukla SA, Sholl LM et al. Association of polymerase e-mutated and microsatellite-instable endometrial cancers with neoantigen load, number of tumor-infiltrating lymphocytes, and expression of PD-1 and PD-L1. JAMA Oncol 2015;1:1319-1323.

32 Gooden MJ, de Bock GH, Leffers N et al. The prognostic influence of tumour-infiltrating lymphocytes in cancer: a systematic review with meta-analysis. Br J Cancer 2011;105:93-103.

33 Vestal DJ, Jeyaratnam JA. The guanylate-binding proteins: emerging insights into the biochemical properties and functions of this family of large interferon-induced guanosine triphosphatase. J Interferon Cytokine Res 2011;31:89-97.

34 Naschberger E, Croner RS, Merkel S et al. Angiostatic immune reaction in colorectal carcinoma: Impact on survival and perspectives for antiangiogenic therapy. Int J Cancer 2008;123:2120-2129.

35 Britzen-Laurent N, Lipnik K, Ocker M et al. GBP-1 acts as a tumor suppressor in colorectal cancer cells. Carcinogenesis 2013;34:153-162.

36 Shenoy AR, Wellington DA, Kumar P et al. GBP5 promotes NLRP3 inflammasome assembly and immunity in mammals. Science 2012;336:481-485.

37 Kolb R, Liu GH, Janowski AM et al. Inflammasomes in cancer: a double-edged sword. Protein Cell 2014;5:12-20.

38 Nishimura H, Nose M, Hiai $\mathrm{H}$ et al. Development of lupus-like autoimmune diseases by disruption of the PD-1 gene encoding an ITIM motif-carrying immunoreceptor. Immunity 1999;11:141-151.

39 Ishida Y, Agata Y, Shibahara K et al. Induced expression of PD-1, a novel member of the immunoglobulin gene superfamily, upon programmed cell death. EMBO J 1992;11:3887-3895.

40 Ahmadzadeh M, Johnson LA, Heemskerk B et al. Tumor antigen-specific CD8 $\mathrm{T}$ cells infiltrating the tumor express high levels of PD-1 and are functionally impaired. Blood 2009;114:1537-1544.

41 Dong H, Strome SE, Salomao DR et al. Tumorassociated B7-H1 promotes T-cell apoptosis: a potential mechanism of immune evasion. Nat Med 2002;8: 793-800.

42 Kim J, Myers AC, Chen L et al. Constitutive and inducible expression of b7 family of ligands by human airway epithelial cells. Am J Respir Cell Mol Biol 2005;33:280-289.

43 Lee SK, Seo SH, Kim BS et al. IFN-gamma regulates the expression of B7-H1 in dermal fibroblast cells. J Dermatol Sci 2005;40:95-103.

44 Parsa AT, Waldron JS, Panner A et al. Loss of tumor suppressor PTEN function increases B7-H1 expression and immunoresistance in glioma. Nat Med 2007;13: 84-88.

45 Marzec M, Zhang Q, Goradia A et al. Oncogenic kinase NPM/ALK induces through STAT3 expression of immunosuppressive protein CD274 (PD-L1, B7-H1). Proc Natl Acad Sci USA 2008;105:20852-20857.

46 Molinari F, Frattini M. Functions and regulation of the PTEN gene in colorectal cancer. Front Oncol 2013;3: 326.

47 Velcheti V, Schalper KA, Carvajal DE et al. Programmed death ligand-1 expression in non-small cell lung cancer. Lab Invest 2014;94:107-116.

48 Spranger S, Spaapen RM, Zha Y et al. Up-regulation of PD-L1, IDO, and T(regs) in the melanoma tumor microenvironment is driven by CD8(+) T cells. Sci Transl Med 2013;5:200ra116.

49 Boland JM, Kwon ED, Harrington SM et al. Tumor B7-H1 and B7-H3 expression in squamous cell carcinoma of the lung. Clin Lung Cancer 2013;14:157-163.

50 Herbst RS, Soria JC, Kowanetz M et al. Predictive correlates of response to the anti-PD-L1 antibody MPDL3280A in cancer patients. Nature 2014;515: $563-567$.

51 Zou W. Regulatory $\mathrm{T}$ cells, tumour immunity and immunotherapy. Nat Rev Immunol 2006;6:295-307.

52 Francisco LM, Salinas VH, Brown KE et al. PD-L1 regulates the development, maintenance, and function of induced regulatory T cells. J Exp Med 2009;206: 3015-3029.

53 Fatokun AA, Hunt NH, Ball HJ. Indoleamine 2,3-dioxygenase 2 (IDO2) and the kynurenine pathway: characteristics and potential roles in health and disease. Amino Acids 2013;45:1319-1329.

54 Fallarino F, Grohmann U, Vacca C et al. T cell apoptosis by kynurenines. Adv Exp Med Biol 2003;527: 183-190.

55 Munn DH, Shafizadeh E, Attwood JT et al. Inhibition of $\mathrm{T}$ cell proliferation by macrophage tryptophan catabolism. J Exp Med 1999;189:1363-1372.

56 Uyttenhove C, Pilotte L, Theate I et al. Evidence for a tumoral immune resistance mechanism based on tryptophan degradation by indoleamine 2,3-dioxygenase. Nat Med 2003;9:1269-1274.

57 Brandacher G. Prognostic value of indoleamine 2,3-dioxygenase expression in colorectal cancer: effect on tumor-infiltrating T cells. Clin Cancer Res 2006;12: 1144-1151.

58 Ferdinande L, Decaestecker C, Verset L et al. Clinicopathological significance of indoleamine 2,3-dioxygenase 1 expression in colorectal cancer. $\mathrm{Br} \mathrm{J}$ Cancer 2012;106:141-147.

59 Nayak A, Hao Z, Sadek R et al. A Phase I study of NLG919 for adult patients with recurrent advanced solid tumors. J Immunother Cancer 2014;2(Suppl 3): P250.

60 Liu X, Shin N, Koblish HK et al. Selective inhibition of IDO1 effectively regulates mediators of antitumor immunity. Blood 2010;115:3520-3530.

61 Murray MF. Tryptophan depletion and HIV infection: a metabolic link to pathogenesis. Lancet Infect Dis 2003;3:644-652.

62 Ghanipour A, Jirstrom K, Ponten F et al. The prognostic significance of tryptophanyl-tRNA synthetase in colorectal cancer. Cancer Epidemiol Biomarkers Prev 2009;18:2949-2956.

Supplementary Information accompanies the paper on Modern Pathology website (http://www.nature.com/ modpathol) 